\title{
The Relationship of the Feces Protein Particles to Rice Protein Bodies ${ }^{\dagger}$
}

\author{
Yonemi Tanaka, Shinsaku Hayashida and Motoyoshi Hongo \\ Laboratory of Applied Microbiology, Department of Agricultural Chemistry, \\ Kyushu University, Fukuoka, Japan
}

Received September 10, 1974

\begin{abstract}
Feces protein particles (FPP), spherical or oval in shape, $1.0 \sim 3.5 \mu$ in diameter, which were observed in the fresh feces of the Japanese, in an average density of $5 \times 10^{\circ} / \mathrm{g}$, resembled the rice protein bodies (RPB) in electron-microscopical fine structure. The FPP decreased in the feces of the man who had been given a rice-free diet consisting of steamed sweet potato; when boiled rice had been fed, the FPP increased, and reached the level of the original density within 5 days. The FPP were concluded to be derived from an indigestible fraction of the RPB which were supplied to the Japanese with the daily intake of rice.
\end{abstract}

As shown in a previous paper, ${ }^{1)}$ spherical or oval particles, $1.0 \sim 3.5 \mu$ in diameter, were observed in the fresh feces of the Japanese, reaching a density of more than $2 \times 10^{\circ} / \mathrm{g}$, and interfered with the decrease in BOD of night soil in the course of the microbiological treatment. Morphologically, the particles were quite similar to yeast cells, but no cellular structure was recognized in the particles, and the concentrical striation lines were observed under the light-microscope. The density of FPP, more than $2 \times 10^{9} / \mathrm{g}$, was also far larger than that of yeasts in the feces, $2 \times 10^{4} / \mathrm{g}$. We called these unknown proteinous particles Feces protein particles (FPP).

This paper proved qualitatively that the FPP were derived from the rice protein bodies (RPB) which present in rice endosperm, ranging from $1.5 \mu$ to $4.0 \mu$ in diameter. ${ }^{2)}$

\section{MATERIALS AND METHODS}

Isolation of FPP. The fresh feces from Japanese adults were collected in a closed vessel and stored at $4^{\circ} \mathrm{C}$. The whole amount of feces was suspended in 15 fold weight of deionized water, sifted through 10 mesh, centrifuged at $2700 \times g$ for $5 \mathrm{~min}$. The precipitate, a crude preparation of FPP, was suspended in 10-fold weight of deionized water over the starting feces, centrifuged at $170 \times g$ for $5 \mathrm{~min}$. The fluid was again centrifuged at $2700 \times g$ for $5 \mathrm{~min}$. The precipitate

\footnotetext{
$\dagger$ Microbiological Treatments of Wastes. Part II.
}

was re-suspended in 10-fold weight of deionized water. After standing for $15 \mathrm{~min}$, the liquid part was collected by decantation, subjected to the centrifugation at $2700 \times g$ for $10 \mathrm{~min}$. The precipitate was suspended in 7.5-fold weight of deionized water, centrifuged at $2700 \times g$ for $10 \mathrm{~min}$. Muddy precipitate was used for electron-microscopical observation as a purified preparation of FPP.

Electron-microscopy. The isolated preparation of FPP was fixed with glutaraldehyde and successively with $1 \%$ osmium tetraoxide and $2 \%$ mironig buffer ${ }^{31}$ pH 7.2 , for $2 \mathrm{hr}$, at $0^{\circ} \mathrm{C}$, dehydrated by an acetone series, embedded in epoxy resin, sliced and poststained with uranyl acetate and lead hydroxide for electronmicroscopic observation.

In vivo-tests of the FPP excretion. Human subjects, a man aged 38 (weight: $61 \mathrm{~kg}$ ) and an woman aged 34 (weight: $51 \mathrm{~kg}$ ), were fed on a rice-containing diet for 3 days. From the breakfast of the 4 th day, the ricecontaining diet was changed to a rice-free diet consisting of steamed sweet potato, and it was continued for 5 days. From the breakfast of the 9 th day, the diet was returned to the rice-containing one. During these two weeks, the whole amount of feces every day was stored in a closed vessel at $4^{\circ} \mathrm{C}$, and the density of FPP was measured every day by Thoma's haemacytometer. The diet consisted of a staple food and a subsidiary food. As the staple food, raw polished rice was boiled for $20 \mathrm{~min}$ in 1.5 -fold water in the case of the rice-containing diet, and sweet potato was steamed for $40 \mathrm{~min}$ in the case of the rice-free diet. As the subsidiary food for both diets, some beef, pork, fish, pumpkin, onion, carrot and cabbage were seasoned with soy sourse, sugar, oil and vinegar. The weight of the rice-containing diet per day was $620 \mathrm{~g}$ as raw 


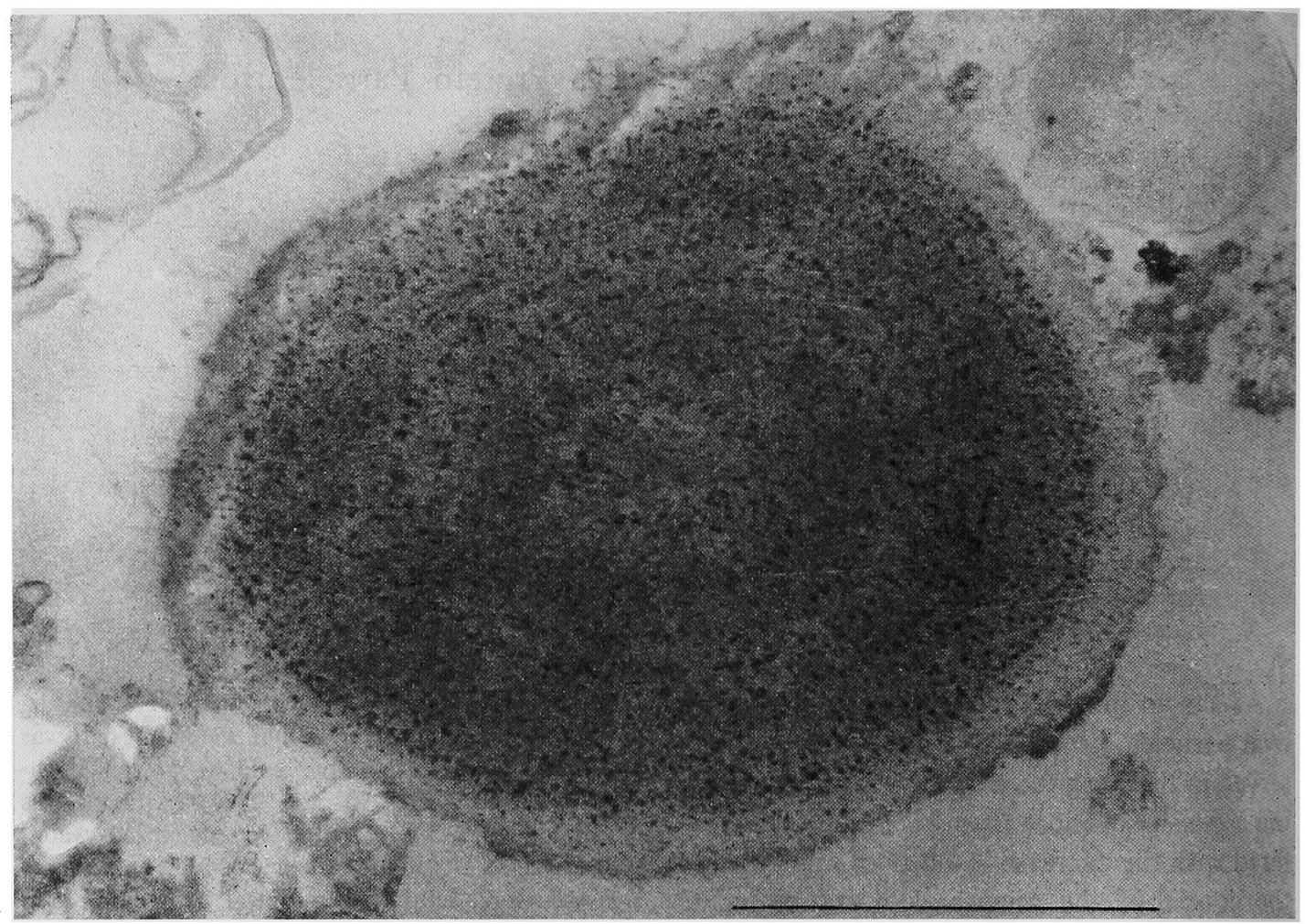

FIg. 1. Electron-micrograph of Thin Section of the Feces Protein Particle.

Bar in figure represents $1 \mu$.

polished rice and $340 \mathrm{~g}$ of cooked subsidiary food for a male, and $370 \mathrm{~g}$ as raw polished rice and $550 \mathrm{~g}$ of cooked subsidiary food for a female respectively. The weight of the rice-free diet per day was $610 \mathrm{~g}$ of raw sweet potato and $340 \mathrm{~g}$ of cooked subsidiary food for a male, and $520 \mathrm{~g}$ of raw sweet potato and $550 \mathrm{~g}$ of cooked subsidiary food for a female respectively. Green tea and milk were fed freely. The diet was given at three times on a day.

\section{RESULTS}

\section{Fine structure of FPP}

The electron-micrograph of FPP, as shown in Fig. 1, revealed that the FPP had a distinct concentric strata structure, which consists of electron-dense and electron-thin layers arrayed alternatively and the respective electron-dense layers appeared to be composed of electrondense fine granules, about $150 \AA$ in diameter. Such a strata structure found in the FPP had been also observed electron-microscopically in the RPB by Mitsuda et al.;2) this unexpected agreement suggested that the FPP were different from yeast cells or parasite's eggs, and were derived from the RPB in the daily diets.

\section{Variation in the density of FPP by diets}

For the purpose of confirming the above suggestion, the interrelationship between the intake of rice and the density of FPP excreted, was pursued. When the rice-free diet was begun to be fed in the 4th day's morning to the persons who had been given the rice-containing diet, as shown in Fig. 2, the density of FPP excreted on the 5th day markedly decreased, and bordered on absence on the 7th day. The average weight of feces per day from the 1st to 3rd day of rice-containing diet intake was $105 \mathrm{~g}$ (moisture: $77.5 \%$ ) in a male and $165 \mathrm{~g}$ (moisture: $77.5 \%$ ) in a female respectively. The average weight of feces per day from the 7th to 9 th day, when the rice-free diet was given, was $170 \mathrm{~g}$ (moisture: $81.0 \%$ ) in a male and $230 \mathrm{~g}$ (moisture: $82.0 \%$ ) in a female respec- 


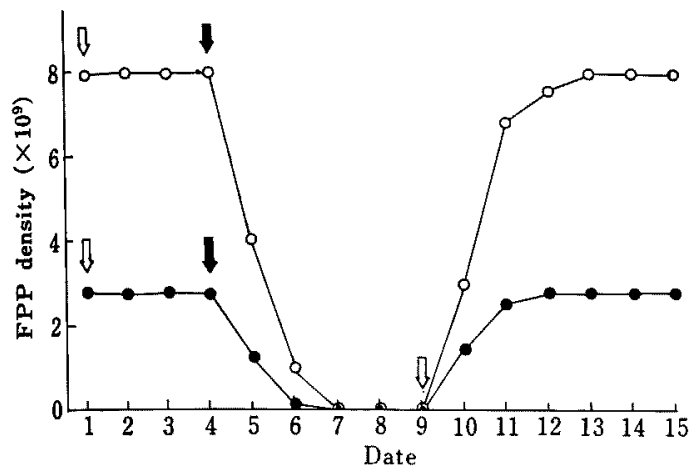

FIG. 2. Variation in the Density of Protein Particles by Diets.

$\sqrt{3}$ shows that from the breakfast on the indicated day, the rice-containing diet was given. $\$$ shows that the rice-free diet had been given from the breakfast on the indicated day.

O, FPP density in male;, FPP density in female. gradually on the 10th day, returning to the level of the original FPP density on the 14th day, as shown in Fig. 3 (Photo. B). The FPP proved to be derived directly from the intake of rice-containing diet.

\section{DISCUSSION}

Most of the protein in rice grains is localized in subcellular storage particles, spherical or oval in shape, 1.5 to $4.0 \mu$ in diameter, which are commonly called "Rice protein bodies (RPB)." Mitsuda et al. isolated the RPB by a differential centrifugation, and revealed that the RPB were composed of $60 \%$ protein and the residual constituents were mainly lipid and carbohydrate. As reported previously, the purified preparation of the FPP, spherical or oval

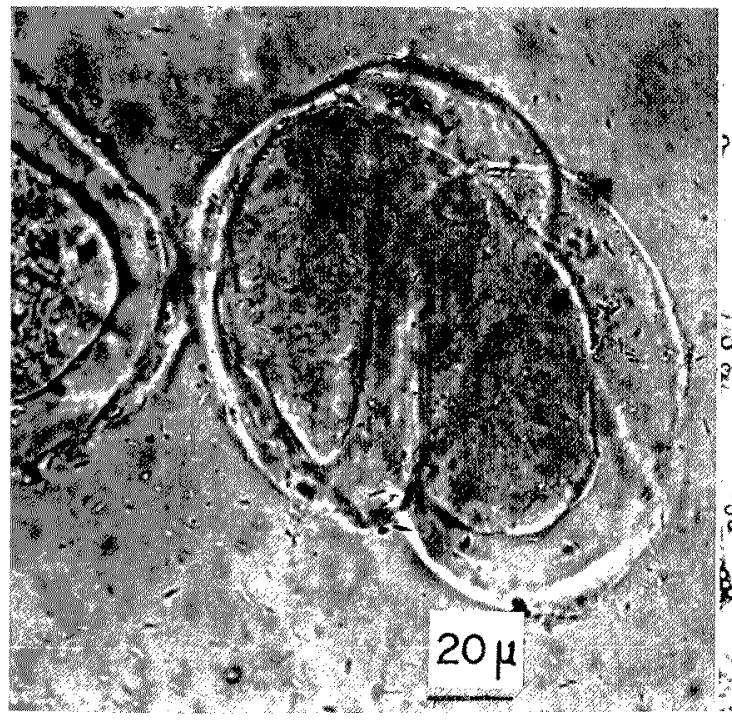

Photo. A

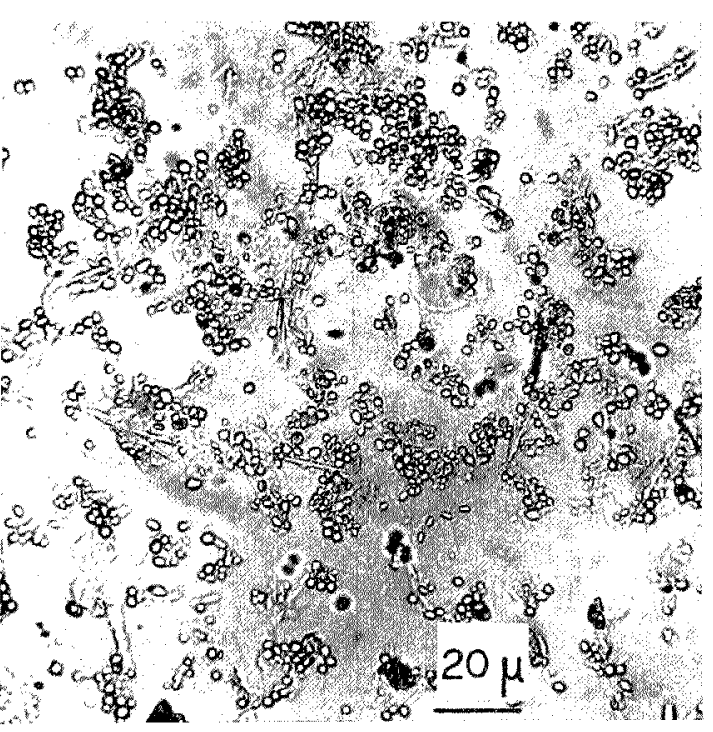

Photo. B

FIG. 3. Light-micrographs of Human Feces.

Photo. A. Feces in the case of feeding rice-free diet, on the 8 th day in the in vivo-test of the FPP excreting.

Photo. B. Feces in the case of feeding rice-containing diet, on the 14 th day in the same test.

tively.

Figure 3 (Photo. A) is a light-micrograph of the feces obtained on the 8th day; no FPP was observed, but the cell wall fragments of sweet potato and bacterial cells were. When the human subjects were re-fed on the rice-containing diet in the 9th day's morning, the FPP increased in shape, $1.0 \sim 3.5 \mu$ in diameter, consisted of $60 \%$ protein, $15.6 \%$ crude fat. The FPP and the RPB were quite similar to each other in size, shape and chemical composition. The electron-micrograph of FPP coincided with that of RPB in fine structure; the numerous granules of about $150 \AA$, arranged in a concen- 
tric stratification, as observed in the RPB by Mitsuda et al. Furthermore, the density of FPP in feces varied with the kind of diet. The intake of the rice-free diet consisting of steamed sweet potato led to a marked decrease in the FPP. All the data, above-mentioned, clearly demonstrated that the FPP originated in the RPB which were supplied to the Japanese in the daily intake of boiled rice.

As will be demonstrated quantitatively in the following papers, however, the digestibility of each individual RPB is found to be different, according to the in vitro-tests, 15 to 20 percent of the whole RPB existing in rice polish is indigestible and excreted as the FPP.

Acknowledgment. We wish to express our sincere thanks to the Emeritus Prof. Y. Tomiyasu, Kyushu University, for his encouragment throughout this work. Thanks are also due to Prof. M. Murakami, Kurume University, for his guidance on the electron-microscopy.

\section{REFERENCES}

1) Y. Tanaka, S. Hayashida and M. Hongo, Nippon Nôgeikagaku Kaishi, 49, 69 (1975).

2) H. Mitsuda, K. Murakami, T. Kusano and K. Yasumoto, Arch. Biochem. Biophys., 130, 678 (1969).

3) G. Millonig, J. Biophys. Cytol., 11, 736 (1961). 